\title{
INTERVENCIÓN DELICTIVA Y ORGANIZACIÓN. NECESIDAD Y COMPLEJIDADES DE UNA COMPARACIÓN FUNCIONAL ENTRE EL DERECHO CHILENO Y EL DERECHO INTERNACIONAL Y COMPARADO*
}

\author{
PARTIES TO THE CRIME AND ORGANISATION. ON THE NEED AND \\ THE COMPLEXITY OF A FUNCTIONAL COMPARISON BETWEEN \\ CHILEAN, INTERNATIONAL AND COMPARATIVE LAW
}

\section{JaIme Couso $^{* *}$}

\begin{abstract}
RESUMEN: El derecho penal internacional y el derecho estatal de varios países han desarrollado nuevas formas de atribuir responsabilidad penal a quienes, sin ejecutar directamente los crímenes, se han vinculado de alguna forma con el grupo u organización en cuyo seno se han cometido. El derecho chileno desconoce algunos de estos desarrollos, con lo cual su "capacidad de rendimiento" podría ser menor a la de aquellos otros ordenamientos. Esta conclusión, con todo, solo puede extraerse con seguridad mediante un análisis jurídico comparado, desde una perspectiva funcional. El artículo precisamente da inicio a un análisis de ese tipo, identificando y examinando los principales desafíos metodológicos que impone, y advirtiendo también sobre la necesidad de evaluar críticamente esas nuevas formas de atribuir responsabilidad penal, desde el punto de vista de importantes principios del derecho penal.
\end{abstract}

Palabras clave: Derecho penal internacional, derecho penal comparado, formas de intervención delictiva, organización delictiva.

ABSTRACT: International criminal law and the domestic law of several countries have developed new ways of ascribing criminal responsibility to those who, without having committed the crimes themselves, were linked to the group or organization within which they were committed. Chilean criminal law is unaware of some of these developments, so that its "problem-solving capacity" could be lower than that of those other legal systems. This conclusion however can only be properly reached through a comparative legal analysis, with a functional approach. This article precisely initiates such an analysis, identifying and examining the main methodological challenges it poses, while pointing out as well the need of a critical assessment of those new modes of criminal liability from the point of view of important principles of criminal law.

Key words: International criminal law, comparative criminal law, modes of liability, criminal organization.

\footnotetext{
Este artículo fue preparado durante una pasantía de investigación en la Universidad Humboldt de Berlín, que pude realizar gracias al semestre sabático que me concedió la Universidad Diego Portales, y al apoyo de la Fundación Alexander von Humboldt, que financió mi beca, así como gracias a la gentileza de mi anfitrión, el Profesor Gerhard Werle, Catedrático de Derecho penal, Derecho internacional, Derecho procesal penal e Historia del Derecho, de la Universidad Humboldt de Berlín. Agradezco las observaciones críticas de Antonio Bascuñán, Claudia Cárdenas, Héctor Hernández, Fernando Londoño y Alex van Weezel a una primera versión de este trabajo, que tuve a la vista al preparar esta nueva versión (por lo demás, bastante más reducida), y que, sobre todo, me llevaron a concebir un proyecto de investigación de más largo aliento, en el que espero abordar con la profundidad debida las nuevas complejidades de la cuestión señaladas por ellos.

** Profesor Titular de Derecho Penal, Universidad Diego Portales, República 112, Santiago. E-mail: jaime.couso@mail.udp.cl
} 


\section{INTRODUCCIÓN}

La comisión de crímenes en contextos organizados plantea un importante desafío al derecho penal: cómo imputar debidamente responsabilidad penal a quienes, sin haber ejecutado directamente los crímenes, han tenido algún tipo de intervención o vinculación con el grupo u organización en cuyo seno han sido cometidos. El derecho penal internacional y los ordenamientos jurídicos de diversos países han desarrollado instituciones especiales para enfrentar ese desafío, en relación con constelaciones fácticas paradigmáticas en a lo menos tres campos: el de la criminalidad estatal o paraestatal, el de la criminalidad organizada y el de la criminalidad empresarial.

El derecho interno chileno conoce algunos de estos desarrollos, pero varios otros no están contemplados expresamente en la ley, o cuentan con escaso reconocimiento en la doctrina y poca o nula recepción jurisprudencial. La sección 1 de este artículo reseña las instituciones jurídicas y los contextos en los que nuestro derecho parece estar quedándose atrás.

La identificación de las diferencias o "asimetrías regulativas" existentes, en esta materia, entre nuestro derecho interno y el derecho penal internacional o el derecho penal de otros estados es relevante, por diversas razones. Que nuestro derecho no tenga la misma "capacidad de rendimiento" que estos otros sistemas jurídicos para imputar responsabilidad penal en contextos organizados puede ser un problema. Si el derecho chileno deja en la impunidad comportamientos que tales ordenamientos castigan, o los sanciona de una forma muy diversa, por ejemplo, castigando solo a título de encubrimiento un comportamiento que en ellos es tratado como una forma de autoría, es importante saberlo. Ya, en primer lugar, porque esta situación de asimetría regulativa podría tener consecuencias en el plano del derecho penal internacional o de nuestros objetivos de cooperación internacional en materia judicial. Fuera de ello, si otros ordenamientos jurídicos, partiendo de objetivos y principios similares a los que inspiran al nuestro, se han visto en la necesidad de desarrollar nuevas formas de imputación penal en este campo, hay entonces una razón adicional para examinar si realmente nuestro derecho se está quedando atrás. La sección 2 de este artículo se ocupa de las principales razones a favor de comparar nuestro derecho y el de aquellos otros sistemas jurídicos, en eta materia.

Ahora bien, antes de concluir que efectivamente tenemos un déficit de capacidad de rendimiento para la imputación penal en contextos organizados, la tarea de comparar sistemas jurídicos plantea varias complejidades, que obligan a mirar más allá de las diferencias de denominación de las respectivas instituciones, o de las distintas opciones de técnica regulativa disponibles para imputar responsabilidad o para diferenciar la intensidad de la respuesta penal. Es necesario, entonces, intentar una "comparación funcional" entre los diversos sistemas jurídicos tenidos a la vista, que atienda a su capacidad efectiva, a través de diversos instrumentos jurídicos, para responder -en su caso, de manera diferenciada- a la intervención en contextos organizados. La sección 3 del artículo da inicio una comparación de este tipo en el campo de la cointervención delictiva en contextos organizados, e identifica y examina los desafíos metodológicos que impone, explorando algunas soluciones.

Por último, aun si de una comparación funcional resultase confirmada la hipótesis de que existen asimetrías regulativas entre nuestro derecho y los demás ordenamientos 
jurídicos relevantes para la comparación, la decisión de mantener nuestro derecho penal a una prudente distancia de la evolución del derecho internacional y comparado en esta materia podría estar justificada, a lo menos respecto de algunos de estos desarrollos. Pues la justificación de la decisión de adecuar nuestra legislación o jurisprudencia a los desarrollos de esos ordenamientos jurídicos no se desprende directamente de la constatación de que existen tales asimetrías regulativas; todavía sería necesario evaluar críticamente esos desarrollos, no solo según su "capacidad de rendimiento" para imputar responsabilidad penal, sino también desde el punto de vista de su corrección normativa, es decir, su consistencia con los principios de responsabilidad individual (o responsabilidad por el hecho propio) y de culpabilidad. El artículo concluye justamente llamando la atención sobre la posibilidad de que, a lo menos, algunos de los nuevos desarrollos en materia de imputación de responsabilidad en contextos organizados sean problemáticos desde el punto de vista de estos principios, al punto de poner en duda la justificación de una adecuación de nuestro derecho, a su respecto.

El artículo, así, al iniciar la revisión de nuestro derecho penal, respecto de alguna de las constelaciones fácticas relevantes, comparándolo con el derecho penal internacional y el derecho penal de algunos estados que, por razones iuscomparativistas, importan especialmente, pretende justificar la necesidad de continuar con esa tarea respecto de todas las constelaciones fácticas relevantes, a la vez que señalar -y "modelar" performativamente- cuál es la metodología mediante la cual se puede llegar a resultados concluyentes: precisamente una comparación de carácter funcional. Por último, advierte que ninguna conclusión de lege ferenda o de sententia ferenda se dejaría extraer de los resultados de la comparación, si no se examina críticamente las diferencias regulativas desde el punto de vista de principios normativos, cuyo alcance y consecuencias en este campo todavía habría que determinar. Con ello no se habrá resuelto, ciertamente, el problema, pero sí se habrá demostrado su existencia, justificado la necesidad de abordarlo, señalado la metodología a seguir y los principios a tener en cuenta, habiendo emprendido, además, la tarea siquiera de forma inicial.

\section{EL DERECHO CHILENO ANTE LOS NUEVOS DESARROLLOS DEL DERECHO PENAL INTERNACIONAL Y COMPARADO}

\section{NeCESIDAD POLÍTICO-CRIMINAL DE UNA AMPLIACIÓN DE LA RESPONSABILIDAD PENAL POR LA INTERVENCIÓN EN CONTEXTOS ORGANIZADOS}

La necesidad de imputar responsabilidad penal y sancionar debidamente a individuos que no han ejecutado directamente los crímenes cometidos, pero que han tenido algún tipo de intervención o de vinculación con grupos u organizaciones en cuyo seno tales crímenes han sido ejecutados por otros individuos, es un problema central de la política criminal comparada e internacional. La insuficiencia de las estructuras de imputación empleadas comúnmente en el derecho penal estatal, como la coautoría, ha sido señalada, sobre todo, cuando se trata de perseguir y castigar crímenes cometidos en el seno de entidades complejas -como las organizaciones criminales, las empresas con tendencia criminal y los estados o entidades paraestatales-, que cuentan con un gran número de miembros, estruc- 
turas jerárquicas y formas de interacción y comunicación selectivas, entre sujetos que, a menudo, ni siquiera se conocen entre sí ${ }^{1}$.

El derecho penal internacional (DPI), en particular, para hacer frente a las peculiares características de la criminalidad organizada ha impulsado en las últimas décadas -desde la segunda mitad del siglo XX, y sobre todo desde los años noventa ${ }^{2}$ - el desarrollo jurisprudencial y estatutario de nuevas formas de imputación de responsabilidad, a través de categorías jurídicas que capten esas complejidades ${ }^{3}$. La propia Corte Penal Internacional (CPI) parece sugerir esta necesidad, que no se vería satisfecha por la categorización de formas de intervención delictiva conocidas en los derechos penales estatales:

"In the view of the Majority, both the Romano Germanic and the Common Law legal systems have developed principles about modes of liability. However, at their inception, neither of these systems was intended to deal with the crimes under the jurisdiction of this Court, i.e. the most serious crimes of concern to the international community as a whole" 4 .

["Desde el punto de vista de la mayoría, tanto el sistema jurídico romano germánico como el del common law han desarrollado principios acerca de los modos de intervención punible. Sin embargo, en sus orígenes, ninguno de estos sistemas estuvo destinado a tratar con los crímenes sometidos a la jurisdicción de esta Corte, a saber, los crímenes más graves de los que se debe ocupar la comunidad internacional en su conjunto".]

Por esa razón, según la misma CPI, los preceptos del Estatuto de Roma ${ }^{5}$, que se refieren a las diversas formas de intervención en un delito

"should be interpreted in a way that allows properly expressing and addressing the responsibility for these crimes" 6 .

["deberían ser interpretados de un modo que permita expresar e imputar adecuadamente la responsabilidad por estos crímenes”.]

En todo caso, las especiales características de la criminalidad colectiva ya habían sido tenidas en cuenta por la jurisprudencia de la Sala de Apelaciones del Tribunal Penal Internacional para la ex Yugoslavia (TPIY), especialmente cuando acuñó formas de imputación delictiva específicas para los miembros de un grupo o empresa criminal, a partir de la constatación de que

\footnotetext{
1 V., por todos, LAmpe (1994) pp. 694-695, 745, abogando de lege ferenda por el establecimiento de normas penales específicas para sancionar estos "sistemas de injusto constituidos" (verfaßte Unrechtssysteme).

2 Werle (2011) nm 14 y ss.

3 Para una reseña de los planteamientos a favor de una dogmática penal especial para la imputación de "comportamientos macrocriminales", v. Амвоs (2005) pp. 148 y ss.

${ }^{4}$ Lubanga Dyilo CPI-TC (2012) parág. 976.

5 Estatuto de la Corte Penal Internacional (Estatuto de Roma) de 2002.

${ }^{6}$ Lubanga Dyilo CPI-TC (2012) parág. 976.
} 
"Most of the time these crimes do not result from the criminal propensity of single individuals but constitute manifestations of collective criminality: the crimes are often carried out by groups of individuals acting in pursuance of a common criminal design"?.

["Muy a menudo estos crímenes no son producto de la inclinación criminal de individuos particulares, sino que constituyen manifestaciones de criminalidad colectiva: los crímenes con frecuencia son ejecutados por grupos de individuos persiguiendo un designio común”.]

Ante aquella característica de los crímenes colectivos, de ser ejecutados en cumplimiento de un plan conjunto, en el que participan muchas personas, más allá de los ejecutores directos, la Sala de Apelaciones del TPIY entiende que el objetivo de su Estatuto ${ }^{8}$ es

"to extend the jurisdiction of the International Tribunal to all those "responsible for serious violations of international humanitarian law" committed in the former Yugoslavia" .

["extender la jurisdicción del tribunal internacional a todos aquellos "responsables de graves violaciones del derecho internacional humanitario" cometidas en la ex Yugoslavia”.]

Con ello, este tribunal quiere poner especial énfasis en que no solo deben responder penalmente quienes directamente ejecutan el hecho, sino también quienes lo ordenan, lo planean, cooperan con él e, incluso, quienes se embarcan en una empresa criminal con otros, para su comisión conjunta, por todos ellos o por algunos de los miembros del grupo $^{10}$. De hecho, en general, se considera que un desafío del DPI en relación con las formas de intervención delictiva es hacer responsables a los individuos de nivel más alto, o de mayor rango, involucrados en la comisión de crímenes derecho internacional, de una forma acorde con ese nivel o rango, a pesar de que ellos se encuentran normalmente "lejos" de la ejecución material de los crímenes ${ }^{11}$, en la que normalmente intervienen sujetos de menor rango o de más bajo nivel de autoridad o poder, pues

"el grado de responsabilidad penal a menudo no disminuye al crecer la distancia respecto de la ejecución material del crimen, sino que suele aumentar” (Werle, 2011, nm 447).

\footnotetext{
7 Tadić TPIY-AC (1999) parág. 191.

${ }^{8}$ En particular, de la disposición que establece las formas de intervención delictiva en el hecho, el Art. 7(1) del Estatuto del TPIY de 1993.

9 Tadić TPIY-AC (1999) parág. 189, citando entre comillas el Art. 1 del Estatuto del TPIY de 1993 (las comillas, y el énfasis en all, están en el original).

10 Pues, circunscribir la respuesta penal solo a los ejecutores materiales "would diregard the role as co-perpetrators of all those who in some way made it possible for the perpetrator physically to carry out that criminal act", Tadic TPIY-AC (1999), parág. 189-190.

11 Manacorda y Meloni (2011) p. 160.
} 
Ahora bien, como se sostendrá en la última sección de este trabajo, la imposición de responsabilidad a los individuos que no han ejecutado directamente los crímenes no se puede efectuar a cualquier costo. Para cumplir con ese desafío -hoy se insiste, con razónlos principios de responsabilidad individual y de culpabilidad no son transables ${ }^{12}$. De hecho, el propio TPIY, al acuñar uno de los modes of liability ("formas de intervención delictiva”) más cuestionados desde el punto de vista del principio de responsabilidad individual ${ }^{13}$, se preocupó de advertir que reconocía la importancia de este principio, conforme al cual

"nobody may be held criminally responsible for acts or transactions in which he has not personally engaged or in some other way participated"14.

["nadie puede ser declarado penalmente responsable por acciones o conciertos en los que no se ha involucrado personalmente o en los que no ha participado de alguna otra manera".]

El desafío político-criminal que se viene examinando tiene, entonces, una complejidad añadida: se trata de que quienes han intervenido en contextos organizados, sin haber ejecutado directamente los crímenes, respondan "debidamente", es decir, en la medida de su responsabilidad individual y de su culpabilidad. También desde ese punto de vista deben ser valoradas las instituciones que han sido desarrolladas en las últimas décadas.

\section{LAS NUEVAS FORMAS DE IMPUTACIÓN PARA CONTEXTOS ORGANIZADOS}

Los principales desarrollos para hacer frente a aquella necesidad político-criminal se han producido en el campo de la así llamada "macrocriminalidad política" (Ambos, 2005, pp. 44 y ss.) o la criminalidad de "los estados o de formaciones estatales criminalmente pervertidos" ("[k] riminell pervertierte Staaten und staatliche Gebilde"15), campo para el cual la jurisprudencia de los tribunales internacionales ${ }^{16}$ ha desarrollado especialmente las figuras de la "responsabilidad del superior jerárquico" (command liability o superior

\footnotetext{
12 V. Werle (2012) nm 497; WerLe (2011) nm 470; y WerLe (2009) nm 464; traduciendo la expresión inglesa principle of individual guilt como Schuldprinzip o "principio de culpabilidad". En este trabajo, en cambio, se utiliza la expresión "principio de responsabilidad individual" o de "responsabilidad por el hecho propio", para significar la prohibición de imputar responsabilidad penal a un individuo por un hecho ajeno, y se reserva la expresión "principio de culpabilidad" para la proscripción del castigo por consecuencias que no han sido abarcadas por el dolo (o la culpa, si para la respectiva figura delictiva viene al caso) del respectivo interviniente. Sobre el primer principio, v., entre nosotros, VAN WeEzel (2011) p. 553, sosteniendo que la imputación del "hecho total" en los crímenes de competencia de la CPI no puede fundamentarse en "una imputación ex iniuria tertti", de modo que "es preciso imputar -como asunto de su competencia- el contexto a cada individuo o bien al colectivo de los intervinientes".

${ }^{13}$ La así llamada "forma extendida" (extended form) de la responsabilidad por la participación en una empresa criminal conjunta (Joint Criminal Enterprise, o JCE); v. infra, el apartado siguiente, en esta sección.

14 Tadić TPIY-AC (1999), parág. 186.

15 LAMPe (1994) pp. 700.

16 Sobre todo, la jurisprudencia de los tribunales penales internacionales ad hoc para la ex Yugoslavia (TPIY) y para Ruanda (TPIR).
} 
responsability $)^{17}$ y la responsabilidad por la participación en una "empresa criminal conjunta" (Joint Criminal Enterprise, o $J C E)^{18}$. Fuera de ello, en años recientes, a partir de la noción del "dominio del hecho" (control over the crime), la CPI ha acuñado la figura de la "coautoría mediata" (indirect co-perpetration) ${ }^{19} \mathrm{y}$, en su primer fallo condenatorio, pronunciado en el caso Lubanga Dyilo ${ }^{20}$, afirmó la posibilidad de imputar coautoría a quienes implementan planes conjuntos, aun cuando estos no sean per se criminales, si ellos dan lugar a la comisión de crímenes.

La primera figura, la responsabilidad del superior jerárquico, es una creación del DPI, que alcanzó el estatus de derecho consuetudinario internacional21 ${ }^{21}$ y fue más tarde recogida expresamente por el Art. 28 del Estatuto de Roma. En esta disposición, sin embargo, la figura tiene un alcance tal que hace compleja la identificación de su naturaleza jurídica, pues parece combinar: (i) la responsabilidad por la omisión de impedir la comisión de crímenes por parte de los subordinados, con (ii) la responsabilidad por la omisión del deber de vigilancia a los subordinados, de la que resulte la comisión de esos crímenes e, incluso, con (iii) la responsabilidad por la omisión de denunciar o de sancionar a los mismos subordinados, una vez que ya han cometido tales crímenes ${ }^{22}$.

La segunda figura, la JCE, tiene raíces en el derecho angloamericano ${ }^{23}$, donde originalmente permitía sancionar hipótesis de exceso de un interviniente, en la coautoría, cubiertas por el dolo eventual del otro, pero, en la jurisprudencia del TPIY extiende su alcance (precisamente en la así llamada "forma extendida" o "tercera forma" de la JCE, en adelante, JCE III) al punto de que permite castigar, a quienes participaron en el plan conjunto, por cualquier crimen que sea una "consecuencia natural y previsible" de la implementación del plan, como auténticos autores de dicho crimen ${ }^{24}$, y ello en contextos en que, por esos "crímenes en exceso" sería difícil afirmar la presencia de dolo eventual en los no

\footnotetext{
17 V., por todos, van Sliedregt (2003) pp. 118 y ss.: Ambos (2005) pp. 295 y ss.; Burghardt (2008) passim; y MeLONI (2010) passim.

18 V., por todos, van Sliedregt (2003) pp. 94 y ss.: Ambos (2005) pp. 75 y ss., 186 y ss.; y, en detalle, HaAn (2008) passim.

19 V. Werle y Burghardt (2011) pp. 202 y ss., con referencias a las primeras decisiones de la CPI. V. también ya JeSSBERGER y Geneus (2008) p. 859 y n. 29, haciendo notar la novedad que a este respecto representa esta decisión de la CPI en el caso Katanga y Chui, pero sin analizar el asunto, por no ser el objeto de ese trabajo.

20 Lubanga Dyilo CPI-TC (2012), parág. 984.

21 Burghardt (2008) pp. 78 y ss.

22 V. Meloni (2010) pp. 197-200; Burghardt (2008) pp. 402 y ss.; Burghardt (2010) pp. 699-700; WerLE (2011) nm 503 y ss.; si bien con algún importante matiz de diferencia entre ellos: mientras para WerLE y BURGHARDT, la responsabilidad del superior jerárquico no llega a abarcar auténticas hipótesis de comisión por omisión de los crímenes ejecutados por los subordinados, que serían sancionables directamente como formas de comisión del respectivo crimen, para MeLONI, en cambio, la comisión por omisión sí queda abarcada por el Art. 28 del Estatuto de Roma (junto a la responsabilidad del superior por no sancionar ni castigar el crimen ya cometido por los subordinados).

23 Van Sliedregt (2003) p. 104; Smith, Hogan y Ormerod (2005) pp. 168-169.

24 D’Ascoli (2011) posición 5800-5821; Tadić TPIY-AC (1999) parág. 190 y ss.
} 
ejecutores. Así, la figura presenta ciertos rasgos de una responsabilidad por la pertenencia a una organización criminal ${ }^{25}$.

Como ya se anticipó, en forma adicional a esas dos figuras, en años recientes, a partir de la noción del "dominio del hecho", proveniente de la dogmática penal "de cuño alemán" ${ }^{26}$, la CPI ha imputado responsabilidad, mediante otras figuras, a quienes participan de un determinado acuerdo de cuya implementación resulte la comisión de crímenes, incluso si estos son ejecutados por sujetos que no participaron de dicho acuerdo (indirect co-perpetration ${ }^{27}$ ), y aun cuando se haya tratado de un plan que no sea per se criminal $^{28}$.

Ahora bien, fuera del campo de la macrocriminalidad política, de la que se ha ocupado el derecho penal internacional, también en otros ámbitos ha habido desarrollos importantes, indicativos de la necesidad creciente y universal de hacerse cargo del factor organizativo a la hora de imputar responsabilidad penal individual. En ese contexto destacan los desarrollos en el derecho estatal comparado en materia de tratamiento de la "criminalidad organizada", en sentido estricto, así como de la "criminalidad de empresa".

En el área de la criminalidad organizada, en sentido estricto, que podría caracterizarse por estar organizada de manera permanente para la obtención ilícita de lucro ${ }^{29}$, los principales desarrollos para la atribución de responsabilidad penal parecen estar constituidos, de un lado, por la tipificación de delitos de pertenencia a una organización ${ }^{30}$, incluyendo su extensión a terceros ajenos a la organización, conforme al modelo del "concurso externo" del derecho italiano ${ }^{31}$, y, del otro, por el castigo autónomo de actos preparatorios (sin necesidad de que el crimen conspirado o auxiliado principie a ejecutarse), como la conspiración ${ }^{32}$ o la facilitación de medios (por ejemplo, el financiamiento del terrorismo ${ }^{33}$ ).

En el área de la criminalidad empresarial ${ }^{34}$, la creciente complejidad de las organizaciones empresariales unida a la circunstancia de que estas, aunque con cierta frecuencia son fuente de delitos, en general no han sido creadas para cometerlos, impone serios desafíos a la imputación de responsabilidad individual en este contexto. El estrecho parentesco con las otras formas de criminalidad en contextos organizados ha sido suficientemente desta-

\footnotetext{
25 Ambos (2005) pp. 76, 82; v., también, Manacorda y Meloni (2011) p. 165, afirmando que "the so-called 'extended form' of JCE fails to fit snugly into the concept of perpetration".

${ }^{26}$ Y que fuera asumida por la jurisprudencia de la CPI como doctrina del control over the crime; v. Katanga y Ngudjolo Chui CPI-PTC (2008), parág. 498.

27 Katanga y Ngudjolo Chui CPI-PTC (2008), parág. 490 y ss.

28 Lubanga Dyilo TC (2012), parág. 984; v. críticamente, Ambos (2012).

29 V. Carnevali (2010) pp. 284 y ss.; v. también, Guzmán Dalbora (1998) passim.

30 V. De Francesco (1994); Grisolía (2004).

31 Sobre la base de la regla de concurso de personas del Art. 110 del Código Penal italiano; cfr. ViGANO (2007) p. 23 y Bernardi (2010) pp. 88 y ss., con abundante bibliografía de referencia; Romano y Grasso (2005) Art. 110/94: 186. Agradezco especialmente a Fernando Londoño haber llamado mi atención sobre este desarrollo del derecho italiano y haberme proporcionado estas referencias.

32 Sobre todo, en el derecho angloamericano; v. SMITH, Hogan y Ormerod (2005) pp. 168-169.

33 V., por ejemplo, la sección 18 USC $\$ 2339$ C, del U.S. Code de 2012.

34 Agradezco especialmente a Héctor Hernández su orientación en relación con los desarrollos habidos en este campo, en el derecho comparado, así como haberme proporcionado varias de las referencias aludidas en este párrafo.
} 
cado desde un punto de vista teórico ${ }^{35}$, pero sobre todo ha dado lugar en el derecho comparado, principalmente por vía jurisprudencial, a formas especiales de imputación. Junto a la alternativa de considerar a los directivos de la empresa como garantes de vigilancia, que responden si omiten impedir la comisión de delitos en el seno de la empresa conforme a los principios de la comisión por omisión ${ }^{36}$, destacan, entre otros desarrollos, la peculiar aplicación que hace la jurisprudencia alemana en el ámbito empresarial de un "dominio de organización" (en un sentido muy diverso al que Roxin da a esta categoría ${ }^{37}$ ), y especialmente, la responsabilidad penal por el hecho de otro (responsabilité pénale pour autrui) del derecho francés ${ }^{38}$ y la doctrina del oficial corporativo responsable (responsible corporate officer doctrine) de la jurisprudencia estadounidense ${ }^{39}$, construcciones que despiertan dudas sobre su compatibilidad con los principios de responsabilidad por hecho y de culpabilidad.

Las instituciones desarrolladas en esos tres campos, para imputar responsabilidad penal a quienes no ejecutan directamente los crímenes cometidos en contextos organizados, han tenido muy diversos grados de reconocimiento en la legislación y jurisprudencia chilena, o en la discusión doctrinaria nacional. Así, por ejemplo, algunas de las instituciones que tienen su origen en la dogmática penal "de cuño alemán", como la autoría mediata por utilización de aparatos organizados de poder, han alcanzado reconocimiento por la doctrina chilena y por alguna jurisprudencia de los tribunales superiores de justicia ${ }^{40}$, mientras que otras, como es el caso de la responsabilidad penal de los directivos de las empresas por omisión de impedir los delitos cometidos en el seno de estas, todavía gozan de escaso reconocimiento doctrinario y jurisprudencial ${ }^{41}$. Otras instituciones, sobre todo las que provienen del derecho angloamericano, como la joint criminal enterprise o la responsible corporate offcer doctrine parecen desconocidas en Chile, y lo mismo ocurre con la responsabilité pénale pour autrui. Por último, algunas formas de intervención surgidas del DPI, como la responsabilidad del superior jerárquico, o la coautoría mediata, no han tenido oportunidad de ser planteadas en el debate jurisprudencial, pese a que la primera de ellas fue incorporada por el Art. 35 de la Ley $N^{\circ} 20.357^{42}$. Por lo que respecta a los desarrollos propios del campo de la criminalidad organizada, si bien han sido objeto de atención por el legislador chileno y la doctrina $^{43}$, han encontrado escasa aplicación jurisprudencial.

\footnotetext{
35 V., por ejemplo, LAMPe (1994) p. 197, identificándola como uno de los casos de "sistemas de injusto constituido" (verfaßte Unrechtssysteme); v. también Mañalich (2011) p. 281.

36 Como ocurre en Suiza, España y, crecientemente, en Alemania; v. un panorama en Hernández (2013) pp. 547-582.

37 Así, Rotsch (2000) p. 536 ss.; cfr. también NACK (2006) pp. 343 ss. V., en todo caso, el análisis de MuÑoz Conde (2001) pp. 620 y ss. del posible rendimiento de la noción roxiniana del "dominio del hecho", en el campo de la criminalidad de empresa y de otras organizaciones "no apartadas del derecho".

38 V. Larguier y Conte (2004) pp. 34 ss.

39 V. Block y Voisin (1992) pp. 1347-1374, con referencias a la jurisprudencia fundamental.

40 V. Hernández (2011) pp. 393 y ss.; Guzmán Dalbora (2007) p. 110.

41 Hernández (2008) pp. 175-198; Hernández (2013) pp. 547-582.

42 Ley $\mathrm{N}^{\circ} 20.357$ de 2009. V. Couso (2012) pp. 111 y ss.

43 v. Guzmán Dalbora (1998); Grisolía (2004); Carnevali y Fuentes (2008); Mañalich (2011); Medina (2013).
} 
Así, al contrastar en una primera mirada las instituciones con que cuenta el derecho interno chileno con las desarrolladas por el DPI y el derecho comparado de algunos ordenamientos jurídicos estatales relevantes para Chile para hacer frente al desafío de atribuir responsabilidad penal por la intervención delictiva en contextos organizados a quienes no han ejecutado directamente los crímenes, surgen claros indicios de diferencias o asimetrías regulativas, que podrían traducirse en una diversa "capacidad de rendimiento" de uno y otros sistemas para alcanzar ese objetivo.

\section{III. ¿POR QUÉ ES RELEVANTE CONSTATAR LA DIVERSA “CAPACIDAD DE RENDIMIENTO" DE LA REGULACIÓN CHILENA?}

Esta pregunta admite varias respuestas, que se relacionan con la cuestión general de qué razones hacen necesario emprender estudios de derecho penal comparado ${ }^{44}$. De esas razones, además, se desprende una primera determinación de los ordenamientos jurídicos con los que es más relevante hacer la comparación.

De acuerdo con una conocida categorización ${ }^{45}$, los estudios de derecho comparado pueden clasificarse en atención al tipo de interés que los guía y la actividad jurídica que se quiere apoyar en ellos, distinguiéndose entre la "comparación jurídica legislativa" (legislative Rechtsvergleichung), la "comparación jurídica judicial” (judikative Rechtsvergleichung) y la "comparación jurídica teórico-científica" (wissenschaftlich-theoretische Rechtsvergleichung). Así, en primer lugar, la necesidad de prestar atención a la regulación ofrecida por otros ordenamientos jurídicos puede venir indicada por necesidades legislativas, en el momento de creación de nuevas normas de derecho interno, teniendo en cuenta que "el derecho se desarrolla principalmente pidiendo prestado" (developing by borrowing) ${ }^{46}$ de otros ordenamientos. En segundo lugar, la atención a la regulación ofrecida por otros ordenamientos jurídicos puede venir indicada por la necesidad de los tribunales de un estado, antes de aplicar una determinada regla de derecho interno, de verificar si acaso se da o no uno de los presupuestos de aplicación de la misma, que justamente consista en que el derecho de otro país disponga o no algo (por ejemplo, tipifique o no como delito cierta conducta) ${ }^{47}$. Finalmente, y a diferencia de esos dos casos de "investigación aplicada", el estudio de otros ordenamientos jurídicos puede estar desprovisto de una finalidad "práctica" y obedecer a un puro interés por la "investigación básica" (Grundlagenforschung o basic research), consistente en una "mejor comprensión del propio derecho" 48.

Ahora bien, por lo que respecta al interés en la comparación entre la regulación dada a las formas de intervención delictiva por el derecho chileno, de una parte, y por el DPI aplicado por la CPI, de la otra, tal comparación podría ser necesaria, en primer lugar, por una necesidad legislativa que, a primera vista, podría trascender el simple interés en

\footnotetext{
44 Sobre esta cuestión general, v. EsER (1998) pp. 1506 y ss.

45 V. EsER (1998) p. 1506, refiriéndose al análisis comparativista de ZwEIGERT y KÖTZ, así como al ofrecido por el civilista Zitelmann.

46 Alan Watson, citado por EsER (1998) p. 1511.

47 ESER (1998) pp. 1507 y ss.

48 ESER (1998) p. 1519, 1516.
} 
"developing by borrowing". Chile es un Estado Parte del Estatuto de Roma, y se obligó a perseguir a nivel interno, por los tribunales chilenos, los crímenes de derecho internacional contemplados por dicho Estatuto. Para posibilitar o facilitar el cumplimiento de este deber ${ }^{49}$, promulgó una ley que tipifica especialmente esos crímenes en el derecho interno, la Ley $\mathrm{N}^{\circ} 20.357$, que, como se vio, incluso incorpora a lo menos una forma de intervención delictiva nueva, contemplada en el Estatuto, la "responsabilidad del superior jerárquico" por omisión de impedir delitos por parte de sus subordinados (Art. 35), sin perjuicio de su responsabilidad por impartir una orden de cometerlos (Art. 36). Pero, ¿qué pasa si ese esfuerzo de adecuación de la legislación interna a las exigencias del Estatuto de Roma no fue completo, en relación con las formas de intervención delictiva?

De acuerdo con el "principio de complementariedad", la CPI adquiere competencia para perseguir crímenes de derecho internacional cuando los Estados Partes con jurisdicción sobre los mismos no tienen voluntad o posibilidad de perseguirlos ${ }^{50}$, lo que, en un caso extremo, podría ocurrir si ciertas formas de imputación reconocidas por el Estatuto de Roma no tienen cabida en el respectivo Estado, dejando en la impunidad a nivel del derecho interno un hecho que ante la CPI sería punible ${ }^{51}$.

Sin embargo, dado el carácter excepcional de la competencia de la CPI, que opera solo en casos graves, y en defecto de una intervención jurisdiccional de los propios esta$\operatorname{dos}^{52}$, la posibilidad de que una discrepancia entre el derecho penal aplicado por la CPI y el derecho interno de un Estado Parte del Estatuto de Roma pueda dar lugar a una intervención de la CPI es más bien remota, solo imaginable en casos extremos, que acarreen impunidad de graves crímenes internacionales o la imposición de penas ridículamente bajas, en virtud de títulos de imputación insignificantes (por ejemplo, encubrimiento), a personas que han desempeñado un papel de primer orden en la ejecución de tales crímenes. La política de la Fiscalía de la CPI, conforme a la cual se propone "to take action only where there is a clear case of failure to take national action" 53 , si bien fue formulada para la "fase inicial"

49 Sobre la existencia de tal deber, que recaería en los Estados Partes del Estatuto de Roma, v. WerLe (2011) nm 197-199.

50 Así Werle (2012) nm. 262 y ss.; v. también CÁrdenas (2007) pp. 123 y ss. Para una perspectiva integral sobre el principio de complementariedad, con referencias a la situación chilena, v. el volumen coordinado por Cárdenas y Fuentes (2012).

51 La posibilidad de que la jurisdicción complementaria de la CPI se fundamente en la impunidad, a nivel interno, de formas de intervención delictiva punibles bajo el Estatuto de Roma, es admitida indirectamente por BuRGHARDT (2010) p. 702, al examinar si acaso las diferencias regulativas entre el Völkerstrafgesetzbuch (Código Penal Internacional alemán de 2002) y el Estatuto de Roma, relativas a la responsabilidad del superior jerárquico, califican como una hipótesis que podría dar lugar a una jurisdicción complementaria de la CPI, inclinándose por la respuesta negativa, en ese caso particular, porque la regulación del primero recogería en una medida suficiente las hipótesis contempladas por el segundo.

52 V. Cárdenas (2007) pp. 123 y ss.

53 "[I]ntervenir solo donde haya un claro caso de omisión de intervención a nivel nacional", Declaración de la Oficina del Fiscal de la CPI, contenida en un Paper on some policy issues before the Office of the Prosecutions, septiembre de 2003, disponible en: http://www.icc-cpi.int/NR/rdonlyres/1FA7C4C6-DE5F-42B7-8B2560AA962ED8B6/143594/030905_Policy_Paper.pdf [fecha de consulta: 5 de marzo de 2013] (la negrilla es mía). 
de su funcionamiento, parece todavía constituir una regla ${ }^{54}$. Más aun, incluso si la diferencia de regulación se traduce en la impunidad, a nivel interno, de una constelación fáctica punible ante la CPI, se ha considerado que tal diferencia no calificaría como una hipótesis que gatille la jurisdicción complementaria de la Corte, si aquella impunidad "se refiere únicamente al rango más bajo de responsabilidad penal del Estatuto de la CPI" 55 , como ocurriría, por ejemplo, con la responsabilidad por omisión imprudente, por parte del superior jerárquico, de sancionar o denunciar los delitos cometidos por el subordinado. Así, salvo en el evento, improbable, de que nuestro sistema de incriminación de las formas de intervención delictiva deje virtualmente en la impunidad a sujetos a los que el DPI considera intervinientes de primer orden en graves crímenes internacionales, la jurisdicción complementaria de la CPI no es una razón que vuelva problemáticas las asimetrías regulativas en materia de intervención delictiva.

No obstante ello, desde una perspectiva de política jurídica, el hecho de que bajo la legislación chilena ciertos comportamientos que el Estatuto de Roma y la jurisprudencia de la CPI consideran crímenes de derecho internacional puedan quedar impunes, o tengan asociada una pena desproporcionadamente baja, en términos relativos, sí puede convertirse en una razón para tener que examinar con más detenimiento las diferencias o asimetrías regulativas existentes entre uno y otro ordenamiento jurídico, en la medida que puedan poner en tela de juicio la importancia asignada, entre nosotros, a la protección de los derechos humanos y a la condena de los actos que, de diversas formas, los violan ${ }^{56}$, peligro que puede convertirse en un fuerte argumento a favor de "developing by borrowing".

Ahora bien, esa primera razón en apoyo de la relevancia de una investigación jurídica comparada en este campo confiere relevancia al estudio, no solo del Estatuto de Roma, sino también de las fuentes del derecho que, según el Art. 21 del propio Estatuto, la CPI debe tener en cuenta en forma subsidiaria a las fuentes estatutarias: el derecho consuetudinario internacional y los principios generales del derecho derivados de los grandes sistemas jurídicos del mundo ${ }^{57}$. Ello implica conceder gran relevancia, de forma derivativa, tanto a la jurisprudencia de los tribunales ad hoc (el TPIY y el TPIR), muy prolíficos en materia de modes of liability, como a los ordenamientos jurídicos estatales que más influencia han tenido en el desarrollo en este campo: los del common law y los de la tradición "romano germánica" (para seguir usando la expresión de la CPI). A modo de ejemplo sobre lo último, cuando el TPIY acuñó el concepto de Joint Criminal Enterprise, afirmando que tenía base

\footnotetext{
54 La intervención de la CPI en casos que, de hecho, estén siendo perseguidos a nivel nacional todavía se considera como una posibilidad completamente excepcional en WerLE (2012) nm 263 n. 538.

55 Burghardt (2010) 703: “betrifft [...] lediglich den untersten Rangbereich strafrechtlicher Verantwortlichkeit im IStGH-Statut".

56 Que al Derecho penal le corresponda, frente a los crímenes de derecho internacional (también) una "función expresiva”, sobre lo inaceptable de tales crímenes y sobre el valor de los intereses afectados por ellos, es ampliamente admitido a nivel de doctrina y jurisprudencia; v., por todos, WeRLE (2011) nm 99 y n. 201; v. también, FISHER (2012) posición 1450 y ss.

57 V. Werle (2011) nm 184; Burghardt (2011) pp. 239-240.
} 
en el derecho consuetudinario internacional, citó la legislación de Alemania, Holanda, Italia, Francia, Inglaterra y Gales, Canadá, Estados Unidos, Australia y Zambia ${ }^{58}$.

Con independencia de la preocupación por no quedar por atrás del Estatuto de Roma en materia de responsabilidad penal en contextos organizados, el interés en la armonización y adecuación del derecho interno, "tomando prestados" los mejores avances de otros ordenamientos jurídicos, es otra razón a favor de la "comparación jurídica legislativa". En materia de derecho penal, y sin perjuicio del aporte que ciertos ordenamientos jurídicos estatales han tenido (en las últimas décadas, sobre todo los de la dogmática "de cuño alemán”) y seguirán teniendo en nuestro derecho penal, el DPI podría llegar a tener un papel muy importante como modelo, si resulta acertada la predicción de Fletcher, conforme a la cual

"the jurisprudence of the ICC will play a significant role in the further cultivation of general principles of liability on the national level. The Rome Statute will probably be a model for new criminal legislation in legal systems around the world" 59.

["la jurisprudencia de la CPI va a jugar un papel significativo en el ulterior desarrollo de principios generales de responsabilidad a nivel nacional. El Estatuto de Roma probablemente será un modelo para la nueva legislación penal en diversos sistemas jurídicos del mundo".]

En materia de intervención delictiva ello introduce una sana cuota de pluralismo en las fuentes que el derecho chileno -normalmente muy dependiente de la dogmática penal "de cuño alemán"- puede considerar para el "developing by borrowing", teniendo en cuenta que el DPI es un campo de discusión y desarrollo de instituciones jurídico penales influido por diversas tradiciones, no solo, ni principalmente, la del derecho penal de tradición alemana, sino también, y en una medida todavía más importante, la del common law ${ }^{60}$.

En segundo lugar, una necesidad propia de la "comparación jurídica judicial" también puede hacer necesario el examen de la forma en que otros ordenamientos jurídicos resuelven el problema de la responsabilidad penal en contextos organizados. Los tribunales chilenos pueden encontrarse ante la necesidad de determinar con certeza si un determinado comportamiento es punible tanto bajo las leyes chilenas como bajo las de otro Estado determinado. Ello puede ocurrir tanto en el caso de que estos tribunales resuelvan una solicitud de extradición pasiva, como en el caso de que ejerzan jurisdicción extraterritorial subsidiaria en virtud de los principios de "defensa" o de "personalidad", ambas decisiones sujetas al principio de "doble incriminación" ${ }^{1}$. Sin embargo, siendo ese el fundamento, el universo de ordenamientos jurídicos relevantes se abriría demasiado, a prácticamente todos los países del planeta, haciendo inviable un estudio exhaustivo. Además, una investigación así de

58 Tadić TPIY-AC (1999) parágs. 224-226.

59 FleTCHER (2007) p. 111.

60 Así, Ambos (2005) p. 49; Амвоs (2008) p. 71; si bien la CPI ha equilibrado algo la influencia relativa de esas dos tradiciones, en materia de formas de intervención delictiva; v., en este sentido, Werle y BurghardT (2011) p. 197 y ss. Más en general, sobre la influencia de ambas familias jurídicas en la teoría del delito del DPI, MATUS (2008).

61 V. Etcheberry I (2005) pp. 125-126 y 135. 
extensa no podría justificarse por la mera eventualidad de que Chile podría llegar a verse en la necesidad de resolver la cuestión de la doble incriminación con cualquiera de esos países. Pero el problema reduce su complejidad si, por una parte, se tiene en consideración que las formas de imputar responsabilidad tienden a asemejarse entre sí en los ordenamientos de una misma "familia jurídica", de forma que hay una ganancia en identificar a priori asimetrías regulativas en la materia, por ejemplo, entre el derecho chileno y el derecho de algunos países representativos de dos grandes tradiciones o familias jurídicas -el common law y el sistema jurídico "romano germánico"- y, por la otra, el esfuerzo se concentra en países con los que, de hecho, Chile ha hecho mayores esfuerzos de integración, que hagan más probable la necesidad de cooperar judicialmente en esta materia.

Además, la "comparación jurídica judicial" también se justifica por permitir una mejor interpretación del propio derecho interno, cuando se trata de aplicar instituciones que este ha tomado de otro, que precisamente interesa estudiar en su condición de "derecho madre" del derecho interno en esa materia ${ }^{62}$. Así ocurre, como ya se advirtió, respecto de la responsabilidad del superior jerárquico, institución respecto de la cual el "derecho madre" es el Estatuto de Roma.

Por último, también en materia de formas de intervención punible, existe un interés en una "comparación jurídica científica", que no se agote en una labor auxiliar de los objetivos buscados por la "comparación jurídica judicial" y la "legislativa”, sino que se enfoque en un objetivo científico "puro": el estudio de la fenomenología del derecho penal, en este caso, la fenomenología de las instituciones con las que, en diversos sistemas jurídicos, se responde al desafío de imputar responsabilidad penal a quienes, sin ejecutar directamente los crímenes, intervienen en contextos organizados, con la finalidad de identificar la conformación de modelos. Este tipo de estudio exige, en todo caso, complementar los hallazgos fenomenológicos con una comparación de las estructuras generales de desarrollo que se revelan en la comparación ${ }^{63}$.

\section{IV. ¿CÓMO HACER LA COMPARACIÓN?}

\section{El PROBlema Metodológico}

Justificada la necesidad de comparar la "capacidad de rendimiento" del derecho interno chileno con la del DPI y la de algunos de los principales ordenamientos jurídicos estatales, en materia de responsabilidad penal por la intervención en contextos organizados, es necesario relevar algunos desafíos metodológicos específicos que esta tarea impone.

La comparación entre diversas regulaciones legales de un determinado problema, como las formas de intervención delictiva, puede conducir a impresiones engañosas. Así, por ejemplo, como se verá más abajo con mayor detalle, la impresión inicial de que el derecho chileno dejó una laguna al recoger en el Art 35 de la Ley $\mathrm{N}^{\circ} 20.357$ solo algunas de las formas de intervención delictiva establecidas por el Art. 28 del Estatuto de Roma para

\footnotetext{
${ }^{62}$ V. la mención de esta razón para emprender una “comparación jurídica judicial” en EsER (1998) p. 1510.

63 EsER (1998) p. 1519.
} 
el superior jerárquico ${ }^{64}$, puede verse modificada si se consideran otros sectores del ordenamiento jurídico chileno, no de la Parte General, sino de la Parte Especial del derecho penal, como los delitos militares contemplados por el Código de Justicia Militar (CJM), que podrían cumplir una "función semejante" a la de algunas de las "formas de intervención" del referido Art. 28. Más aun, la suposición de que, para evitar cualquier laguna, habría sido preferible reproducir en la ley interna esta disposición, podría pasar por alto que una norma así cumple, en del Estatuto de Roma, una "función" muy diversa a la que cumpliría en el derecho chileno, pues si en el primero es posible reunir bajo un mismo título comportamientos de naturaleza tan diversa entre sí, reservando las distinciones para la muy relevante fase de individualización de las penas, en el sistema de derecho penal chileno, que realiza sus distinciones valorativas fundamentales mediante una diferenciación entre los diversos tipos penales, la reunión de títulos de tan diversa naturaleza bajo una sola conminación penal conduciría a una asimilación valorativamente insostenible ${ }^{65}$. La metodología con la que se emprenda la comparación entre los diversos sistemas jurídicos, entonces, debe ser objeto de una atenta planificación.

De acuerdo con una conocida sistematización en el campo de los estudios comparados de derecho penal ${ }^{66}$, el plan debe partir por la definición del problema social que se pretende abordar mediante una investigación comparada, en términos de una "pregunta funcional" (Funktionalitätsfrage), es decir, una referida a la manera como los diversos ordenamientos jurídicos comparados enfrentan, con distintos instrumentos, el problema. Una vez definida esa "pregunta funcional", es necesario seleccionar los ordenamientos jurídicos que serán comparados, selección que viene determinada por la medida en que la consideración de unos u otros se revele útil para responder a aquella pregunta ${ }^{67}$. En seguida, corresponde estudiar y analizar cada ordenamiento jurídico comparado, realizando además "cortes transversales comparativos" (rechtsvergleichende Querschnitte), destinados a perfilar diferencias y semejanzas en la resolución de las constelaciones problemáticas, y confeccionando "tipologías" de formas de resolución ${ }^{68}$. Por último, puede ser necesaria una valoración político jurídica de las diversas soluciones alternativas de regulación perfiladas, sobre todo si, junto a su eficacia relativa, las diversas opciones regulativas adoptadas por los distintos ordenamientos jurídicos se dejan evaluar desde la perspectiva del respeto a principios jurídicos o políticos importantes. En los apartados siguientes, se sigue esta sistematización para caracterizar las complejidades metodológicas de la forma como debe compararse la regulación chilena, en materia de responsabilidad penal en contextos organizados, con la que ofrecen el DPI y el derecho estatal comparado.

64 Así, Hernández y Millaleo (2010).

65 Así, con matices, a propósito de la regulación escogida por el derecho penal alemán para dar recepción al mismo Art. 28 del Estatuto de Roma, Burghardt (2010) p. 703.

66 V. Eser (1998) pp. 1521 y ss. En ese trabajo, así como en el más reciente de Sieber (2005), se da cuenta de una metodología de estudios de derecho comparado que se ha mostrado especialmente idónea en el campo de la comparación entre diversos sistemas de regulación de la responsabilidad penal, en las investigaciones realizadas por el Max Planck-Institut de Derecho penal comparado e internacional, de Friburgo, Alemania.

67 ESER (1998) p. 1521.

68 ESER (1998) p. 1522. 


\section{LA PREGUNTA FUNCIONAL}

En el caso del problema de que trata este trabajo, la pregunta se refiere a la "capacidad de rendimiento" del derecho chileno para imputar debidamente responsabilidad penal a intervinientes en contextos organizados, que no han ejecutado directamente los crímenes. Las instituciones por medio de las cuales los diversos sistemas intentan resolver ese problema se pueden encontrar en planos distintos: puede tratarse de la configuración de determinadas "formas de intervención" - una cuestión de la "Parte General" del derecho penal-, de la tipificación de un delito de participación en asociaciones ilícitas o en grupos criminales -una solución de "Parte Especial"-, del establecimiento de diferenciaciones significativas a nivel de los criterios de individualización de la pena -recurso muy importante, por ej., en la jurisprudencia de los tribunales penales internacionales $a d h o c^{69}-o$, incluso, de medidas alternativas consideradas por el proceso penal ${ }^{70}$. La inconmensurabilidad inicial entre las soluciones ubicadas en diversos planos (lo que un ordenamiento resuelve mediante diferenciación de formas de intervención, otro lo puede resolver mediante una regla de determinación de pena) aconseja no poner el foco en las instituciones jurídicas en sí, y concentrarse en "el problema social a regular" a través de ellas ${ }^{71}$, y a partir de ese foco comparar todas las instituciones jurídicas, de los diversos ordenamientos, que para la solución de ese problema cumplen con una "función" semejante ${ }^{72}$. Para seguir con el ejemplo empleado al comienzo de esta sección, la atención, entonces, no debe estar centrada en la institución de la responsabilidad del superior jerárquico, del Art. 28 del Estatuto de Roma, sino en el problema de cómo y en qué medida es posible hacer responder al superior que no cometió crímenes, pero que dejó que sus subordinados los cometiera, sin impedirles hacerlo o sin sancionarlos o denunciarlos por haberlo hecho.

Ahora bien, si el problema que destaca como fenómeno socialmente saliente y normativamente relevante es, en términos generales, la posibilidad de imputar debidamente responsabilidad penal a diversos sujetos que intervienen en contextos organizados en los que se producen crímenes, tal como se ha planteado la cuestión interesan, en realidad, más específicamente ciertas "constelaciones fácticas" problemáticas que han sido abordadas, especialmente, por desarrollos recientes del DPI y del derecho estatal comparado. Ellas pueden ser identificadas explorando "detrás" de las nuevas instituciones desarrolladas. Si se atiende a las instituciones reseñadas en la primera sección, en una primera formulación, que puede requerir ulterior precisión, las "constelaciones fácticas relevantes" a las que se debe prestarse atención son:

i) la posibilidad y condiciones de la imputación de responsabilidad penal, por crímenes de derecho internacional, a los superiores jerárquicos de los ejecutores materiales,

\footnotetext{
69 D’Ascoli (2011) posición 9770 y ss., destacando que solo en ese plano se aprecian diferencias en el tratamiento dado a intervenciones directas o indirectas en los crímenes de derecho internacional.

70 V. Sieber (2005) p. 113.

71 ESER (1998) p. 1521.

72 V. Sieber (2005) pp. 112-113; Ambos (2011) $\$ 5$ nm 8.
} 
que no han participado en los crímenes de las formas "tradicionales" (como coautores, autores mediatos, instigadores, o cómplices);

ii) la posibilidad y condiciones de la imputación de responsabilidad penal, por crímenes de derecho internacional, a quienes han participado de un acuerdo o plan conjunto, de cuya implementación resulta la comisión de crímenes más allá de lo previsto en el plan ("crímenes colaterales"), sea porque este no contemplaba la ejecución de crímenes, sea porque se cometieron crímenes "en exceso" del plan, o porque los cometieron sujetos con los que no se celebró el acuerdo;

iii) la posibilidad y condiciones de la imputación de responsabilidad penal a quienes, sin participar en los "delitos-fin" de la misma, y sin controlarla, se vinculan de diversas formas con una organización o grupo orientado de forma permanente a la obtención ilícita de lucro (criminalidad organizada "en sentido estricto"); y

iv) la posibilidad y condiciones de la imputación de responsabilidad penal a los órganos directivos de empresas que no están organizadas para delinquir, pero en cuyo seno no es descartable que se cometan delitos, por su omisión de medidas destinadas a impedir su comisión.

\section{COMPARACIÓN FUNCIONAL}

El explicar, al comienzo de esta sección, el "problema metodológico" que la comparación jurídica impone, se dio cuenta de los riesgos a que conduce una comparación descontextualizada entre las instituciones de unos y otros ordenamientos, y de la necesidad de una comparación que atienda a las funciones desempeñadas por ellas, al interior de cada uno. Aquí se profundiza la cuestión, en relación con el problema de la responsabilidad penal en contextos organizados.

En primer lugar, se plantean cuestiones terminológicas, como la que surge por el diverso sentido que se asigna a las expresiones accomplice y "cómplice", respectivamente, en el derecho angloamericano y en la dogmática penal de los países iberoamericanos o de Italia. Así, por ejemplo, cuando el TPIY aplicó por primera vez la figura de la JCE la trató como una forma de accomplice liability ${ }^{73}$, afirmación de la que podría querer desprenderse que, para el TPIY, la JCE es una forma de intervención de segundo grado, "accesoria” respecto de la autoría -la forma "principal"- ${ }^{74}$, y merecedora de menor pena, como ocurre con la "complicidad" en el derecho penal chileno. Sin embargo, en línea con la terminología del derecho angloamericano -para la cual accomplice no supone, necesariamente, una forma de intervención de segundo rango ${ }^{75}$-, en la jurisprudencia del TPIY, la accomplice liability no representa una forma de intervención de segundo grado, ni siquiera una forma de participación "accesoria", sino una intervención de primer orden, una forma de "cometer el

\footnotetext{
73 Tadić TPIY-AC (1999) parág. 220.

74 Manacorda y Meloni (2011) p. 166.

75 V. Singer y La Fond (2007) pp. 370 y ss.
} 
delito", en el sentido asignado en nuestro medio jurídico a la noción de "autoría" (por lo menos en relación con las dos primeras "formas" de la $J C E^{76}$ ).

Ahora bien, más allá del esfuerzo de una traducción que evite estas confusiones terminológicas, es necesario identificar y comparar con precisión las instituciones que, en cada sistema, enfrentan el mismo tipo de problema", es decir "compare like with like, functional equivalents"78; en este caso, el problema de la posibilidad y condiciones de imputación de responsabilidad penal en cada una de las constelaciones fácticas relevantes, analizando el papel desempeñado en ellas por cada institución.

Esas instituciones, como se dijo, pueden encontrarse en diversos niveles de la regulación penal. Ello obliga, entonces, a efectuar una mirada de conjunto a cada ordenamiento jurídico, examinando cómo, en sus diversos niveles, es abordado y resuelto el problema objeto de investigación ${ }^{79}$.

Así, volviendo al ejemplo de la responsabilidad del superior jerárquico, es necesario explorar si la función que el Art. 28 a) del Estatuto de Roma cumple en relación con las hipótesis no incluidas en el Art. 35 de la Ley $\mathrm{N}^{\circ}$ 20.357, como el castigo de la omisión del jefe militar de sancionar los delitos cometidos por los subordinados, o de su omisión imprudente de impedir la comisión de delitos por parte de los mismos, es cumplida de modo equivalente, por ejemplo, por el Art. 299, $\mathrm{N}^{\circ} 1^{\circ}$ del CJM, que sanciona al superior militar que "no mantenga la debida disciplina en las tropas a su mando o no reprima en el acto cualquier delito militar", con penas que no dependen de la asignada a los delitos cometidos por estos últimos. Al efectuar ese análisis hay que tener en cuenta que, en el Art. 28 del Estatuto de Roma, la regulación unitaria de esas hipótesis de conducta con la de la omisión dolosa de prevenir la comisión de delitos que los subordinados están cometiendo o se proponen cometer no tiene la consecuencia de asimilar la intensidad de pena entre todas esas hipótesis -el Estatuto de Roma ofrece amplia libertad a la CPI para hacer las necesarias diferenciaciones- y que, en cualquier caso, en ninguna de ellas se trataría de consagrar expresamente la responsabilidad del superior como autor, a título de comisión por omisión, de los delitos ejecutados por los subordinados ${ }^{80}$-como sí lo hace, en cambio, el Art. 35 de la Ley $\mathrm{N}^{\circ}$ 20.357-, de modo que, contrariamente a lo que sugieren las apariencias, no cabría apreciar aquí una supuesta "asimetría funcional” consistente en que el CJM esté tratando como una mera omisión propia lo que en el Estatuto de Roma sería una comisión por omisión por parte del superior, en calidad de autor, del delito ejecutado por los subordinados. Por el contrario, castigar la omisión de sancionar y de denunciar (incluso, tal vez, la omisión culposa de prevenir), bajo la regla del Art. 299, $\mathrm{N}^{\circ} 1^{\circ}$, del CJM, funcionalmente -desde el punto de vista de las implicancias prácticas y simbólicas- pareciera guardar mayor semejanza con el tratamiento que el Art. 28 del Estatuto de Roma da a esas mismas

\footnotetext{
76 V. van Sliedregt (2003) pp. 101-102; Ambos (2005) p. 76; Manacorda y Meloni (2011) p. 162; D’Ascoli (2011).

77 Sieber (2005) pp. 112-113; Burghardt (2011) pp. 246; Ambos (2011) $\$ 5$ nm 8.

78 MacCormick y Summers (1997) p. 7 [“comparar lo mismo con lo mismo, equivalentes funcionales”].

79 Sieber (2005) p. 113.

80 Sino, más bien, una forma de responsabilidad residual, de menor gravedad incluso que la complicidad; v. con detalles, Burghardt (2008) pp. 402 y ss., 461-462; Burghardt (2011) pp. 699-700; Werle (2011) nm 503 y ss.
} 
hipótesis de conducta, que lo que sucedería si el legislador las hubiese incluido en el Art. 35 de la Ley $N^{\circ}$ 20.357. Ello todavía no resolvería por completo, en todo caso, la cuestión sobre la equivalencia funcional; solo demostraría, tal vez, la inconveniencia de buscarla mediante una importación del modelo de regulación unitaria adoptado por el Art. 28 del Estatuto de Roma. La comparación funcional requiere algo más.

Para emprender una comparación funcional, que permita dar con "asimetrías funcionales", y no de denominación o técnica regulativa, hay que tener en cuenta, no solo las normas, sino también la jurisprudencia relevante producida a partir de ellas, y la valoración de la doctrina. Incluso es aconsejable, de forma complementaria, estudiar los antecedentes sobre la manera como esas normas funcionan en la práctica, es decir, atendiendo no solo al "law in the books", sino al "law in action" 1 . Una metodología que permite acercarse a esta perspectiva es la de la "comparación jurídico penal basada en casos", que ha sido empleada con éxito en este tipo de estudios de derecho penal comparado ${ }^{82}$. En efecto, al centrar el análisis en el tratamiento que cada ordenamiento jurídico daría a determinadas constelaciones fácticas, basadas en situaciones reales, que presentan de forma completa el problema que es objeto de la investigación, la metodología permite, a partir del juicio de especialistas conocedores de cada sistema jurídico a comparar, examinar de una forma mucho más realista el rendimiento de las diversas instituciones (de Parte General o Parte Especial, incluso, de reglas de determinación de la pena o instituciones procesales) con que cada ordenamiento cuenta.

Ahora bien, sin entrar en una comparación propiamente tal, y manteniendo el análisis todavía en el plano de la identificación de desafíos metodológicos, una mirada preliminar a diversos sistemas de regulación de la cointervención delictiva en contextos organizados, arroja luz sobre diferencias de tratamiento que se vislumbran -entre diversos ordenamientos, o al interior de uno mismo- en a lo menos dos sentidos:

En primer lugar, se puede apreciar una diferencia entre tratar a la organización: (a) como "contexto de imputación", que es lo propio de las "formas de intervención" en el delito, en que el acuerdo de voluntades puede ser un criterio de imputación del hecho a título de coautoría, o la existencia de un aparato organizado de poder puede ser un criterio de imputación a título de autoría mediata, o (b) como "objeto de imputación", como en los delitos de intervención en una organización criminal, o de asociación ilícita ${ }^{83}$. En el DPI, por ejemplo, la conspiracy históricamente ha tenido una doble naturaleza, como el inchoate crime of conspiracy (una forma de anticipación de la punición a un comportamiento preparatorio), y como una forma de intervención en un crimen distinto ${ }^{84}$; pero el Estatuto de

81 ESER (1998) pp. 1521-1522.

82 V. la reseña de Sieber (2005) pp. 118 y ss. La metodología también se usó para comparar la recepción, en diversos países de América Latina, de la figura de la autoría mediata por dominio de aparatos organizados de poder, en la Conferencia Internacional "Los estrategas del crimen y sus instrumentos: El autor detrás del autor en el Derecho Penal latinoamericano”, celebrada del 5 al 7 de octubre de 2010, en Bogotá, Colombia, organizada por el Instituto Max-Planck de Derecho Penal Extranjero e Internacional, la Fundación Alexander von Humboldt y la Universidad Sergio Arboleda, en la que el autor de este trabajo participó.

83 V. esta distinción en MAÑAlich (2011) pp. 283 y ss., incorporando además la consideración de la organización como "sujeto de imputación", que no tiene, en principio relevancia, para las constelaciones fácticas problemáticas a las que se refiere el problema tratado en este trabajo.

84 Van Sliedregt (2003) p. 18. 
Roma renunció a la regulación del crimen de conspiracy, como acto preparatorio punible, permitiendo solo su castigo como forma de intervención en otro delito (que a lo menos haya entrado en fase de tentativa $)^{85}$. La diferencia que puede ser relevante, por ejemplo, para resolver si cabe el concurso de delitos entre el castigo por asociarse con la organización y el castigo por los "delitos-fin" de la misma, efectivamente ejecutados ${ }^{86}$.

En segundo lugar (cuando la organización es "contexto de imputación”), también se aprecia una diferencia entre tratar al respectivo comportamiento: (i) como una infracción de segundo orden, accesoria, a título de participación, o (ii) como una infracción de primer orden, principal, a título de autoría. Podría pretenderse que esta última diferenciación solo sería aplicable a los sistemas diferenciados de intervención delictiva, pues solo ellos considerarían, junto a la autoría, la existencia de formas de participación accesorias, a título de participación, y que no sería, en cambio, practicable en sistemas jurídicos unitarios, como supuestamente lo es el DPI ${ }^{87}$, o el derecho de Italia ${ }^{88}$. Sin embargo un análisis funcional da cuenta de que la distinción entre sistemas unitarios y sistemas diferenciados tiende a simplificar las características de cada sistema jurídico real, que no se ajustan a los modelos ideales ${ }^{89}$, de modo que no puede ser tomada como razón para concluir, sin más, dónde se sitúa cada ordenamiento en relación con esta variable ${ }^{90}$. Por ello, para una comparación funcional es ineludible un examen más matizado de la estructura y contenido de los diversos sistemas de reglas sobre la intervención delictiva, recurriendo -como propone Sieber ${ }^{91}$ a un análisis situado en unos planos de abstracción superiores, más universales (universale Metaebene), en los que lo relevante son las exigencias objetivas y subjetivas que cada sistema formula para imputar el "hecho global" a los individuos que realizan contribuciones individuales. Por ello, las estructuras que subyacen a la distinción entre autoría y participación, aun cuando esta denominación no refleje bien las distinciones que un determinado sistema jurídico pueda realizar en la práctica, sí son relevantes para un análisis situado en un plano "universal", y aluden, sintéticamente, a lo menos a la siguientes variables: (i) la graduación de la diversa intensidad relativa de la respuesta punitiva; (ii) la diferenciación en el plano simbólico de intervenciones de primer orden o de segundo orden; (iii) la accesoriedad de ciertas intervenciones respecto de otras que son tenidas por principales, sin las cuales las primeras no son punibles; y (iv) la relevancia o irrelevancia de formas imperfectas de ejecución de ciertos comportamientos, según si son tenidos por principales o accesorios ${ }^{92}$; sin

\footnotetext{
85 Por todos, Werle (2012) nm 671.

86 V. esta cuestión en Cancio Meliá (2008) pp. 66 y ss.; Silva Sánchez (2008) pp. 108 y ss.

87 Van Weezel (2011) p. 562; v. también, Ambos (2011) \$ 7 nm 13 y n. 65, calificando al Estatuto de Roma como un "sistema unitario de autor de carácter funcional" (funktionalles Einheitstätersystem); STEWART (2012) passim, abogando por un entendimiento radicalmente unitario del sistema de intervención delictiva del Estatuto de Roma.

88 WeISSER (201) pp. 98 y ss

89 V., al respecto, Couso (2012) pp. 96 y ss.

90 V. así, también, Sieber (2005) p. 116; en profundidad sobre la ineptitud de la distinción para caracterizar el derecho alemán, Rostch (2009) pp. 190 y ss.

91 Sieber (2005) p. 113.

92 Couso (2013) pp. 621 y ss.
} 
perjuicio de que esas distinciones pueden perder significación relativa frente a otras que puedan aparecer como, estructuralmente, más significativas, como la afectación "directa” o "indirecta” del bien jurídico ${ }^{93}$.

Desde esa perspectiva, por ejemplo, una comparación entre el tratamiento penal que el Estatuto de Roma (en su Art. 25.3 b) y el derecho chileno (Art. 36 de la Ley No 20.357) dan al superior que imparte una orden de cometer un crimen de derecho internacional no debe contentarse con constatar que, en ambos casos, ese comportamiento se castiga como una forma de intervención por parte del superior en el delito del subordinado, sino que también debe examinar si, en cada caso, se trata de un modo de intervención de primer orden, principal, y respecto del cual son también punibles las formas imperfectas de ejecución, o si acaso en alguno de esos sistemas (o en ambos) se trata tan solo de un modo de intervención de segundo orden, accesorio, que solo es punible cuando la orden es cumplida por el subordinado, siquiera principiando a ejecutar su hecho. Y, justamente, no es clara la equivalencia funcional de ambas regulaciones, teniendo en cuenta las variables recién señaladas. En efecto, en el derecho chileno se trataría de un comportamiento de primer orden, en términos contenido simbólico de reproche y de su punibilidad; accesorio o principal, según si se le califica de inducción o se le considera -aplicando la noción roxiniana del dominio de la organización ${ }^{94}$ - una hipótesis de autoría mediata; que es sancionable -como tentativa- aun cuando el subordinado no comenzó a cumplir la orden (por expresa disposición del Art. 36, inc. $2^{\circ}$, de la Ley $N^{\circ}$ 20.357). Bajo el Estatuto de Roma, en cambio, si bien el tratamiento sería similar en las hipótesis que califiquen como autoría mediata, en las demás se le trataría como un comportamiento accesorio, de segundo orden, menos grave que la autoría -y que la inducción del derecho chileno-, y que no es nada claro que pueda castigarse -como tentativa- si el subordinado no ha cumplido la orden ${ }^{95}$.

No obstante lo anterior, las diferencias (o coincidencias) que puedan presentarse en relación con aquellas variables no deben exagerarse si, por aplicación de las normas que permiten castigar la simple pertenencia o vinculación a la organización -como "objeto de imputación”-, termina por equipararse (o diferenciarse) el tratamiento dado por cada sistema jurídico comparado a las constelaciones fácticas relevantes.

\section{VALORACIÓN NORMATIVA DE LAS INSTITUCIONES ADOPTADAS POR EL DPI Y EL DERECHO ESTATAL COMPARADO}

A lo largo del trabajo se ha dado cuenta de la existencia de indicios relevantes de la presencia de "asimetrías regulativas" entre nuestro derecho y el DPI y el derecho estatal comparado, que podrían afectar la capacidad de rendimiento del primero para imputar responsabilidad penal por crímenes cometidos en contextos organizados, a algunos de quienes no han intervenido directamente en su ejecución. Pero ya en la introducción se advirtió

93 Rotsch (2009) pp. 470 y ss.

94 V. Roxin (2006) pp. 242 y ss.

95 Cfr. Werle (2011) nm 640, quien considera que el asunto no es claro; Ambos (2005) pp. 373-375, en cambio, por razones materiales, defiende la punibilidad de la tentativa. 
sobre la necesidad de evaluar críticamente la corrección normativa de los desarrollos de esos ordenamientos jurídicos, antes de concluir que nuestro derecho debe acogerlos.

La necesidad de realizar este tipo de valoraciones, en un estudio de derecho comparado, depende de los objetivos que se busquen con ella. Desde luego, si se trata de identificar principios generales del derecho, es ineludible una comparación jurídica valorativa, a partir de otros principios vinculantes en el contexto en que se realiza la comparación ${ }^{96}$. En el caso de la imputación de responsabilidad penal en contextos organizados, dos principios fundamentales en juego son, como se anunció, el de responsabilidad individual o responsabilidad por el propio hecho y el de culpabilidad, que permiten un abordaje crítico de desarrollos del derecho comparado y del propio derecho chileno. Las asimetrías funcionales en el plano de la regulación, por tanto, por sí solas no fundamentan conclusiones de lege ferenda o de sententia ferenda, aun cuando sean motivos poderosos para una valoración de la conveniencia y justicia de adopción, en el derecho interno, de los desarrollos más aceptados en el derecho comparado. Un momento valorativo, por tanto, si bien es lógicamente posterior a la identificación de las asimetrías funcionales, no puede ser ignorado.

De hecho, para los propios tribunales penales internacionales es fundamental respetar el principio de responsabilidad individual, o de responsabilidad por el propio hecho, pues, como tempranamente lo planteara H.D. Lewis, en el contexto del debate sobre los Juicios de Nuremberg, "nadie puede ser responsable, en el sentido ético propiamente tal, por la conducta de otro" ("no one can be responsible, in the properly ethical sense, for the conduct of another one" ${ }^{\prime 97}$. Es la advertencia que el TPIY parece haber tenido en cuenta cuando, al acuñar la "forma extendida" de la JCE, se vio en la necesidad de enfatizar que ello no consistía en hacer responder al acusado por un hecho ajeno ${ }^{98}$.

Y el caso es, sin embargo, que algunos desarrollos del DPI y del derecho estatal comparado, a través de los cuales se afirma la responsabilidad de quienes no han intervenido directamente en la ejecución, acusan ciertos rasgos de una "responsabilidad asociativa" (guilt by association), que podría contravenir el principio de responsabilidad individual ${ }^{99}$. Adicionalmente, alguna de las instituciones con que se pretenda imputar responsabilidad a quienes no han ejecutado directamente los crímenes, pero han alcanzado con otros algún acuerdo, eventualmente criminal, podrían afectar el principio de culpabilidad -en el sentido de hacerles responder solo por resultados abarcados por el dolo, o la culpa, si expresamente se la admite-, sobre todo en relación con los delitos cometidos en exceso del plan ${ }^{100}$.

Por ello, una vez que, por medio del análisis de derecho comparado, se identifiquen las instituciones con que los diversos ordenamientos enfrentan el desafío de imputar debidamente responsabilidad penal en contextos organizados, corresponde examinar crítica-

\footnotetext{
96 Ambos (2011) \$9 nm 15, refiriéndose, en el contexto del derecho penal europeo, a una "comparación valorativa” a partir de un principio de maximización de la protección de los derechos fundamentales, v. ibíd., $\$ 5 \mathrm{~nm} 8$.

97 Lewis, 1948, p. 3.

98 V. supra, n. 14 y el texto principal correspondiente.

99 Sobre esos rasgos en el "derecho de Nüremberg", v. van SLIedregt (2003) p. 166 y ss., 21 y ss.; DamGAarD (2008) p. 191 y n. 249.

100 Problema que plantearía, precisamente, la "forma extendida" de la JCE; v. Werle (2011) nm 470; Ambos (2011) \$7 nm 32 .
} 
mente si con ellas no se pone en peligro aquellos principios. Ello podría llegar a decirse, por cierto, no solo de las instituciones de que otros ordenamientos jurídicos disponen, sino también de las del derecho chileno. Así, cuando se evalúe la "capacidad de rendimiento" de unos y otros sistemas, debe considerarse, su capacidad de rendimiento de forma "normativamente admisible".

Ahora bien, la tarea de evaluar críticamente las instituciones con las que se ha procurado hacer responder a los no intervinientes (directos) por crímenes cometidos en contextos organizados, a partir de principio de responsabilidad individual y del principio de culpabilidad, requeriría una determinación más precisa de su estatus (¡tienen rango constitucional ${ }^{101}$ ) y de la forma como operarían imponiendo limitaciones al legislador o al tribunal penal. En relación con lo último, específicamente en lo que atañe al principio de responsabilidad individual o por el hecho propio, es necesario identificar criterios que permitan discernir, en una determinada incriminación punitiva, si acaso ella se apoya o no en la atribución de responsabilidad a un individuo por una conducta ajena. Esta tarea es compleja, como lo revela el debate, por una parte, sobre el fundamento de la punibilidad de la participación ${ }^{102}$, y por la otra, sobre la justificación del castigo $-\mathrm{y}$ el contenido de injusto- de los "delitos de organización"103. Para abordarla, es necesario tener especialmente en cuenta el análisis de la fenomenología de los contextos organizados, sobre todo, la cuestión de si los así llamados "sistemas de injusto constituidos"104 permiten, por su configuración fenomenológica, atribuciones de responsabilidad más amplias que las propias de la coautoría -como "sistema de injusto simple"-, en la medida que esa configuración las convierte en un "objeto de imputación" atribuible al individuo que se vincula a la organización, como una forma de menoscabo relevante de bienes jurídicos a través del peligro abstracto y, con ello, un comportamiento con suficiente contenido de injusto, independiente del injusto de los delitos que cometan otros miembros de la misma ${ }^{105}$, o si acaso esos "sistemas de injusto constituidos" solo pueden ser vistos como un "contexto de imputación" que confiere especial peligrosidad a la vinculación individual al mismo, de modo de permitir una cualificación de la intervención delictiva, pero siempre como una forma de intervención en los "delitos-fin" de la organización, "a través" de esta ${ }^{106} \mathrm{y}$, por ello, sin un contenido de injusto independiente de aquellos.

\section{CONCLUSIONES}

En este trabajo, en primer lugar, se han aportado claros indicios de la existencia de un problema: el derecho penal chileno, desde el punto de vista de su "capacidad de rendi-

\footnotetext{
101 Afirmativamente, entre otros, CURY (2005) p. 388.

102 V. Roxin (2003) \$ 26 nm 8 y ss ; en Chile, entre otros, van WeEzel (2009) pp. 433 y ss.; Couso (2012) pp. 100-101.

103 Mañalich (2011) pp. 289 y ss; y, sobre todo, la discusión entre Cancio Meliá (2008) pp. 66 y ss., y Silva SÁNCHEZ (2008) pp. 108 y ss.

104 LAMPe (1994) pp. 693 y ss.

105 Así, Mañalich (2011) pp. 280 y ss.; Medina (2013) p. 501.

106 Silva Sánchez (2008) p. 108.
} 
miento" para imputar responsabilidad en contextos organizados, podría encontrarse por debajo del DPI y de algunos ordenamientos jurídicos estatales relevantes para Chile, sobre todo al considerar los desarrollos que en las últimas décadas han tenido lugar en aquel y en estos, precisamente con el propósito de mejorar su capacidad de hacer responder a quienes, en tales contextos, no intervienen directamente en la ejecución de los crímenes.

En segundo lugar, se examinaron las razones de política legislativa, de necesidad de aplicación judicial del derecho y de interés teórico-científico, que confieren relevancia a la existencia de "asimetrías regulativas" entre el derecho chileno y esos otros ordenamientos jurídicos.

Todo ello justifica la necesidad de nuevas investigaciones, de largo aliento, que confirmen o desestimen la hipótesis de la existencia de un déficit en la capacidad de rendimiento del derecho penal chileno en este campo y que, en su caso, identifiquen con precisión dónde se produce ese déficit.

También se justificó suficientemente que, para afirmar de manera concluyente la existencia de esas "asimetrías regulativas" y precisar su extensión, no basta con una comparación entre las instituciones legales con que cada ordenamiento jurídico cuenta, pues bien es posible que alguno de ellos, aun cuando parezca formalmente "deficitario" en relación con determinadas instituciones jurídicas, de todos modos consiga en la práctica imputar responsabilidad por medio de otras instituciones jurídicas, con resultados similares; o bien, es posible que la existencia de instituciones nominalmente equivalentes en diversos ordenamientos jurídicos oculte una diversa capacidad funcional, en la práctica, para resolver el problema. Por ello, como se explicó en este mismo trabajo, poderosas razones sugieren la necesidad de efectuar una comparación "funcional”, que parta de los problemas específicos -en este caso, la necesidad de imputar debidamente responsabilidad penal en determinadas "constelaciones fácticas" complejas y relevantes-, y examine las herramientas que, en diversos niveles (Parte General del derecho penal, Parte Especial del derecho penal, reglas de determinación de la pena, instituciones del proceso penal), cada ordenamiento emplea para hacer frente al respectivo problema, y su modo de operar. El artículo dio inicio a un análisis de ese tipo en relación con algunas de las constelaciones fácticas relevantes, en el campo de la macrocriminalidad política, identificando la necesidad de continuarlo, también en relación con constelaciones comunes en el campo de la criminalidad organizada, en sentido estricto, y de la criminalidad de la empresa. Un propósito fundamental de ese ejercicio, que aun está en una fase muy inicial, fue la identificación y examen de los principales desafíos metodológicos que el problema de la organización delictiva plantea a la comparación funcional, y la anticipación de algunos caminos para enfrentarlos.

Por último, el trabajo ofreció razones poderosas, que han sido esgrimidas por la doctrina comparada e internacional, a favor de la necesidad de evaluar críticamente la corrección normativa de las instituciones que han aumentado la "capacidad de rendimiento" de esos otros ordenamientos para imputar responsabilidad en contextos organizados, antes de concluir que en Chile debe avanzarse en la misma dirección, advirtiendo que algunas de aquellas instituciones pueden ser problemáticas desde el punto de vista del principio de responsabilidad por el hecho propio y del principio de culpabilidad. 


\section{BIBLIOGRAFÍA CITADA}

Ambos, Kai (2005): La parte Internacional del Derecho penal Internacional (Uruguay, Duncker \& Humblot - Temis - Konrad Adenauer Stiftung).

Aмвоs, Kai (2008): ¿Cómo imputar a los superiores crímenes de los subordinados en el Derecho penal internacional? Fundamentos y formas (Bogotá, Universidad Externado de Colombia) $185 \mathrm{pp}$.

Ambos, Kai (2011): Internationales Strafrecht (3a edición, München, Verlag C.H. Beck) 586 pp.

Амвоs, Kai (2012) "The first Judgment of the International Criminal Court (Prosecutor v. Lubanga): A comprehensive Analysis of the Legal Issues”, International Criminal Law Review, vol. 12, № 2.

Bernardi, Alessandro (2010): "Seguridad y Derecho Penal en Italia y en la Unión Europea”, Politica Criminal, Vol. 5, No 9: pp. 68-113.

Block, Joseph G. y Voisin, Nancy A. (1992): “The responsible corporate officer doctrine - can you go to jail for what you don't know?” 22 Envtl. L. [Enviromental Law] 1992: pp. 1347-1374.

BuRghARDT, Boris (2008): Die Vorgesetzterverantwortlichkeit im völkerrechtlichen Straftatsystem (Berlín, BWV Berliner-Wissenschaft) 514 pp.

BURGHARDT, Boris (2010): "Die Vorgesetztenverantwortlichkeit nach Völkerstrafrecht und deutschem Recht (\$4 StGB)", Zeitschrift für Internationale Strafrechtsdogmatik (ZIS), 11/2010: pp. 696-711.

Burghardt, Boris (2011): "Die Rechtsvergleichung in der völkerstrafrechtlichen Rechtsprechung”, en S. Beck/C. BurChard/B. FateH-Moghadam (Editores), Strafrechtsvergleichung als Problem und Lösung (Baden-Baden, Nomos Verlagsgesellschaft) pp. 235-254.

Cancio Meliá, Manuel (2008): "El injusto de los delitos de organización: peligro y significado”, en Cancio Meliá y Silva Sánchez, Delitos de Organización (Montevideo-Buenos Aires, B de F) pp. 15-84.

Cárdenas, Claudia (2007): "La Cooperación de los Estados con la Corte Penal Internacional a la luz del principio de complementariedad", Revista de Derecho de la Pontificia Universidad Católica de Valparaíso, XXXIV, $1^{\text {er }}$ Semestre de 2010: pp. 281-304.

CÁrdenas, Claudia y Fuentes, Ximena (Coordinadoras) (2012): Corte Penal Internacional y jurisdicciones estatales. El principio de complementariedad (Santiago, LegalPublishing) 274 pp.

Carnevali, Raúl (2010): “La criminalidad organizada. Una aproximación al derecho penal italiano, en particular la responsabilidad de las personas jurídicas y la confiscación", Revista Ius et Praxis, Año 16, No 2, 2010: pp. 273-330.

Carnevali, Raúl y Fuentes, Hernán (2008): "Informe jurídico sobre la eventual aplicación del delito de asociación ilícita establecido en el art. 16 de la Ley N²0.000”, Polít. crim., No 6, D1: pp. 1-10

Couso, Jaime (2012): "Sobre el estado actual de la noción de autor y partícipe en el derecho chileno. En memoria del Profesor Mario Garrido Montt”, Revista Chilena de Derecho y Ciencias Penales, vol. 1: pp. 91-133. 
Couso, Jaime (2013): "Sobre el concepto material de autor. Consideraciones dogmáticas y metodológicas, en Homenaje al Profesor Enrique Cury”, en Van Weezel, Alex (Editor), Humanizar y renovar el Derecho Penal. Estudios en Memoria de Enrique Cury (LegalPublishing-Thompson Reuters) pp. 619-657.

Cury, Enrique (2005): Derecho penal. Parte general (Santiago, Ediciones Universidad Católica de Chile, octava edición).

Damgand, Ciara (2008): Individual Criminal Responsibility for Core International Crimes (Berlín - Heidelberg, Springer Verlag).

D'Ascoli, Silvia (2011): Sentencing in International Criminal Law. The UN ad hoc Tribunals and Future Perspectives for the ICC (Oxford - Portland, Hart Publishing, versión kindle) s/n de págs.

De Francesco, Giovannangelo (1994): "Dogmatica e politica criminale nei rapporti tra concorso di persone ed interventi normativi contro il crimine organizzato”, Riv. it. dir. proc. pen., 1994: pp. 1266-1303.

ESER, Albin (1998): "Funktionen, Methoden und Grenzen der Strafrechtsvergleichung", en Albrecht, Hans Jörg et al (Editores), Internationale Perspektiken in Kriminologie und Strafrecht. Festschrift für Günther Kaiser zum 70. Geburtstag (Berlín, Duncker \& Humblot) pp. 1499-1529.

Etcheberry, Alfredo (2005): Derecho Penal. Parte General (tomo I, Santiago, Editorial Jurídica de Chile).

FISHER, Kirsten J. (2012): Moral Accountability and International Law (London - New York, Routledge, versión kindle) $s / n^{\circ}$ de págs. (se cita según posición digital de la respectiva referencia).

FletChen, George (2007): The Grammar of Criminal Law (volumen 1, Oxford - New York, Oxford University Press).

Grisolía, Francisco (2004): "El delito de asociación ilícita”, Revista Chilena de Derecho, Vol. $31 \mathrm{~N}^{\circ} 1$ : pp. 75-88.

GuZmán Dalbora, José Luís (2007): “El tratamiento de los crímenes internacionales en la jurisprudencia chilena: Una cabeza de Jano”, en: Lateinamerika Analyzen, No 3 (Hamburg, Institut für Lateinamerika-Studien) pp. 95-122.

Guzmán Dalbora, José Luis (1998): “Objeto jurídico y accidentes del delito de asociaciones ilícitas”, Revista de Derecho Penal y Criminología, 1998-2: pp. 153-207.

HaAn, Verena (2008): Joint Criminal Enterprise. Die Entwicklung einer mittäterschaftlichen Zurechnungsfigur im Völkerstrafrecht (Berlin, Duncker \& Humblot) 362 pp.

Hernández, Héctor (2008): “Apuntes sobre la responsabilidad penal (imprudente) de los directivos de empresa, REJ No 10 (2008): pp. 175-198.

Hernandez, Héctor (2010): "La introducción de la responsabilidad penal de las personas jurídicas en Chile”, Política Criminal, Vol. 5, No 9 (julio 2010): pp. 207-236.

Hernández, Héctor (2011): “Comentario al artículo 10 No 11”, en Couso / Hernández (dir.), Código penal comentado. Parte General. Doctrina y jurisprudencia (Santiago, Abeledo Perrot - LegalPublishing) pp. 382-413.

Hernández, Héctor (2013): "El fundamento de la posición de garante de los directivos de empresa, respecto de delitos cometidos por terceros en la misma”, en VAN WeEZEL, Alex 
(Editor), Humanizar y renovar el Derecho Penal. Estudios en Memoria de Enrique Cury (Santiago, LegalPublishing-Thompson Reuters) pp. 547-582.

Hernandez, Héctor, y Millaleo, Salvador (2010): "Intervención punible de dirigentes en grupos criminales y redes en Chile", informe presentado para la Conferencia Internacional, Los estrategas del crimen y sus instrumentos: El autor detrás del autor en el Derecho penal latinoamericano, Bogotá, Colombia, 5 al 7 de octubre de 2010, inédito.

Jessberger, Florian y Geneuss, Julia (2008): "On the Application of a Theory of Indirect Perpetration in Al Bashir", Journal of International Criminal Justice 6 (2008): pp. 853-869.

LAMPE, Ernst-Joachim (1994): "Systemunrecht und Unrechtssysteme", Zeitschrift für die gesamte Strafrechtswissenschaft 106, 4: pp. 683-745.

Larguier, Jean y Conte, Philippe (2004): Droit pénal des affaires (11 a edición, París, Armand Colin).

MacCormick, Neil y Summers, Robert (Eds.) (1997): Interpreting Precedents. A comparative Study (Aldershot-Brookfield-Singapore-Sydney: Ashgate/Dartmouth) 585 pp.

LEwIS, H. D. (1948): “Collective Responsibility", Philosophy, Volume 23, Nr. 84, January 1948: pp. 3-18.

Manacorda, Stefano y Meloni, Chantal (2011): "Indirect Perpetration versus Joint Criminal Enterprise. Concurring Approaches in the Practice of International Criminal Law?", Journal of International Criminal Justice 9 (2011): pp. 159-178.

Mañalich, Juan Pablo (2011): “Organización delictiva. Bases para su elaboración dogmática en el derecho penal chileno", Revista Chilena de Derecho, vol. 38 N 2: pp. 279-310.

Matus, Jean Pierre (2008): La Transformación de la teoría del delito en el derecho penal internacional (Barcelona-Santiago de Chile, Atelier-Ediciones Jurídicas de Santiago) 185 pp.

MedinA, Gonzalo (2013): "El injusto de la asociación ilícita como problema de la estructura de afectación del bien jurídico”, en Mañalich, Juan Pablo (Coordinador), La Ciencia Penal en la Universidad de Chile. Libro Homenaje a los Profesores del Departamento de Ciencias Penales de la Facultad de Derecho de la Universidad de Chile (Santiago, Facultad de Derecho Universidad de Chile) pp. 481-504.

Meloni, Chantal (2010): Command Responsibility in International Criminal Law (La Haya, $\mathrm{T} \times \mathrm{M} \times \mathrm{C}$ Asser Press).

Muñoz Conde, Francisco (2001): „Willensherrschaft kraft organisatorischer Machtapparate im Rahmen „nichtrechtsgelöster“ Organisationen?“, en Schünemann et al. (edits.), Festschrift für Claus Roxin zum 70. Geburtstag (Berlín-Nueva York, de Gruyter) pp. 609-624.

NACK, Armin (2006): „Mittelbare Täterschaft durch Ausnutzung regelhafter Abläufe“, Goltdammer's Archiv für Strafrecht. pp. 342 y ss.

Romano, M. y Grasso, G (2005): Commentario sistematico del codice penale, vol. II (art 85149), Art. 110/99 ss.

RoTsch, Thomas (2000): „Tatherrschaft kraft Organisationsherrschaft?“, Zeitschrift für die gesamte Strafrechtswissenschaft 112: pp. 518-562.

RоTSCH, Thomas (2009): "Einheitstäterschaft statt Tatherrschaft“(Mohr Tübingen, Siebeck). Roxin, Claus (2006): Täterschaft und Tatherrschaft ( $8^{a}$ edición, Berlín, Walter de gruyter).

Roxin, Claus (2003): Strafrecht. Allgemeiner Teil. Besondere Erscheinigungsformen der Straftat, tomo II (Múnich, C.H. Beck). 
Sieber, Ulrich (2005): "Strafrechtsvergleichung im Wandel. Aufgaben, Methoden und Theorieansätze der vergleichenden Strafrechtswissenschaft", en Sieber, Ulrich/Albrecht, Hans-Jörg (Editores), Strafrecht und Kriminologie unter einem Dach. Kolloquium zum 90. Geburtstag von Professor Dr. D. h.c. mult. Hans-Heinrich Jescheck am 10. Januar 2005 (Berlín, Duncker \& Humblot) pp. 78-130.

Silva SÁnchez, Jesús María (2008): "El injusto de los delitos de organización: peligro y significado", en Cancio Meliá y Silva Sánchez, Delitos de Organización (MontevideoBuenos Aires, B de F) pp. 87-134.

Singer, Richard C. y LA Fond, John Q. (2007): Criminal Law: examples and explanations (Nueva York, Aspen Publishers, cuarta edición).

Smith, Hogan y Ormeron (2005): Criminal Law (Oxford-Nueva York, Oxford University Press, décimo primera edición).

STEWART, James G. (2012): "The end of "modes of liability" for international criminal crimes", Leiden Journal of International Law / Volume 25 / Issue 01 / March 2012: pp 165-219.

Van Sliedregt, E. (2003): The Criminal Responsibility of Individuals for Violations of International Humanitarian Law (La Haya, T×M×C Asser Press).

VAN WeEZEL, Alex (2009): "Intervención delictiva y garantismo penal A la memoria de Juan Bustos Ramírez", Zeitschrift für Internationale Strafrechtsdogmatik. Disponible en: http://www.zis-online.com/dat/artikel/2009_8_350.pdf): pp. 432-445

Van Weezel, Alex (2011): "Problemas de imputación al tipo penal en crímenes contra la humanidad", en Verdugo, Mario (Director), Doctrinas Esenciales. Gaceta Jurídica. Derecho Penal (Santiago, AbeledoPerrot - LegalPublishing, originalmente publicado en Gaceta Jurídica, Doctrina, Estudios, Notas y Comentarios No 305, año 2005) pp. 551-563.

Viganò, Francesco (2007): "La lucha contra el terrorismo de matriz islámica a través del Derecho penal: la experiencia italiana”, Política Criminal, No 3, 2007, A3: pp. 1-27.

WeIsser, Bettina (2011): Täterschaft in Europa (Tubinga, Mohr Siebeck).

Werle, Gerhard (2009): Principles of International Criminal Law (La Haya, T×M×C Asser Press, segunda edición).

Werle, Gerhard (2011): Tratado de Derecho penal internacional (Traducc. de la 2a ed. alemana por Cárdenas, Claudia; Couso, Jaime y Gutiérrez, María, Valencia, Tirant lo Blanch, segunda edición).

Werle, Gerhard (2012), Völkerstrafrecht (Tubinga, Mohr Siebeck).

Werle, Gerhard y Burghardt, Boris (2011), "La co-autoría mediata: ¿desarrollo de la dogmática jurídico-penal alemana en el Derecho Penal Internacional?”, en Revista Penal, No 28: pp. 197-206.

\section{JURISPRUDENCIA CITADA}

Katanga y Ngudjolo Chui CPI-PTC (2008): Corte Penal Internacional, Sala de Cuestiones Preliminares, decisión de 30 de septiembre de 2008.

Lubanga Dyilo CPI-TC (2012): Corte Penal Internacional, Sala de Primera Instancia, 14 de marzo de 2012 (sentencia de primera instancia). Disponible en: http://www.icc-cpi.int/ iccdocs/doc/doc1379838.pdf [fecha de consulta: 1 de diciembre de 2012]. 
Tadić TPIY-AC (1999): Tribunal Penal Internacional para la ex Yugoslavia, Sala de Apelaciones, 15 de julio de 1999 (sentencia en apelación). Disponible en: http://www.icty. org/case/tadic/4 [fecha de consulta: 1 de diciembre de 2012].

\section{NORMAS LEGALES CITADAS}

Code of Laws of the United States of America (U.S. Code) de 2012; Legislación federal de los Estados Unidos de América, sección 18 USC \$2339C.

Código de Justicia Militar, Art. 299.

Código Penal italiano, Art. 110.

Estatuto de la Corte Penal Internacional (Estatuto de Roma) de 17 de julio de 1998, A/ CONF.183/9, enmendado por los procès-verbaux de 10 de noviembre de 1998, 12 de julio de 1999, 30 de noviembre de 1999, 8 de mayo de 2000, 17 de enero de 2001 y 16 de enero de 2002, entró en vigor el 1 de julio de 2002. Aprobado, a nivel del derecho interno chileno, por el Congreso Nacional de Chile el 25 de junio de 2009, su Instrumento de Ratificación se depositó el 29 de junio de 2009 ante el Secretario General de la Organización de las Naciones Unidas (Decreto Promulgatorio $\mathrm{N}^{\circ} 104$, del Ministerio de Relaciones Exteriores, D.O. 1-08-2009), Arts. 21, 25 y 28

Estatuto del Tribunal Penal Internacional para la ex Yugoslavia (Estatuto del TPIY) de 25 de mayo de 1993, adoptado por la Resolución 827 del Consejo de Seguridad de las Naciones Unidas, Arts. 1 y 7.

Ley No 20.357 del 18 de julio de 2009, Tipifica crímenes de lesa humanidad y genocidio y crímenes y delitos de guerra, Arts. 35 y 36.

Völkerstrafgesetzbuch (Código Penal Internacional alemán) de 26 de junio de 2002 (BGBl. I S. 2254).

\section{DOCUMENTOS CITADOS}

Declaración de la Oficina del Fiscal de la CPI, en: Paper on some policy issues before the Office of the Prosecutions, septiembre de 2003. Disponible en: http://www.icc-cpi.int/ NR/rdonlyres/1FA7C4C6-DE5F-42B7-8B25-60AA962ED8B6/143594/030905_Policy_Paper.pdf [fecha de consulta: 5 de marzo de 2013]. 
